\title{
Downregulation of TAP1 in Tumor-Free Tongue Contralateral to Squamous Cell Carcinoma of the Oral Tongue, an Indicator of Better Survival
}

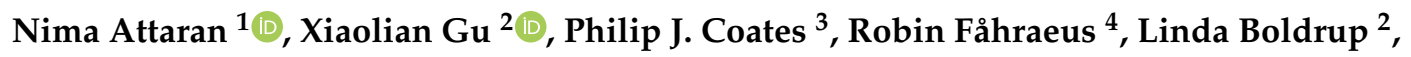 \\ Torben Wilms ${ }^{1}$, Lixiao Wang ${ }^{2}$, Nicola Sgaramella ${ }^{2}$, Katarina Zborayova ${ }^{1}$ and \\ Karin Nylander ${ }^{2, *(\mathbb{D})}$ \\ 1 Department of Clinical Sciences/ENT, Umeå University, SE-901 85 Umeå, Sweden; \\ attaran.nima1@gmail.com (N.A.); torben.wilms@umu.se (T.W.); \\ Katarina.Zborayova@regionvasterbotten.se (K.Z.) \\ 2 Department of Medical Biosciences, Umeå University, SE-901 85 Umeå, Sweden; xiaolian.gu@umu.se (X.G.); \\ linda.boldrup@umu.se (L.B.); lixiao.wang@umu.se (L.W.); sgaramellanicola12@gmail.com (N.S.) \\ 3 RECAMO, Masaryk Memorial Cancer Institute, Zluty kopec 7, 65653 Brno, Czech Republic; \\ p.j.coates91259@gmail.com \\ 4 Institut de Génétique Moléculaire, Université Paris 7, Inserm UMR 1162, 75013 Paris, France; \\ robin.fahraeus@inserm.fr \\ * Correspondence: karin.nylander@umu.se
}

Received: 1 July 2020; Accepted: 26 August 2020; Published: 27 August 2020

\begin{abstract}
Oral cancers are surrounded by epithelium that histologically might seem normal, but genetically has aberrations. In patients with squamous cell carcinoma of the oral tongue (SCCOT), it is therefore important to study not only the tumor but also the clinically tumor-free contralateral tongue tissue that remains in the patient after treatment to map changes of prognostic and/or diagnostic value. The transporter associated with antigen processing (TAP) dimer is a key factor in the process of activating cytotoxic T cells. By downregulating the expression of TAP, tumor cells can escape cytotoxic $\mathrm{T}$ cell recognition. Biopsies from tumor and clinically tumor-free contralateral tongue tissue in 21 patients with SCCOT were analyzed together with tongue biopsies from 14 healthy individuals, which served as the control group. Dividing patients into TAP1-high and TAP1-low groups according to the median TAP1 level in tumor-free samples showed that patients with lower TAP1 mRNA levels in tumor-free samples had better overall $(p=0.003)$ and disease-free survival $(p=0.002)$. The results showing that TAP1 levels in tumor-free tongue tissue contralateral to the SCCOT correlate with survival is an important contribution to early diagnosis and follow up of SCCOT.
\end{abstract}

Keywords: TAP1; SCCOT; field cancerization; MHC I

\section{Introduction}

In Sweden, approximately 160 new cases of squamous cell carcinoma of the tongue (SCCOT) are detected annually, making it the most frequent tumor in the oral cavity. Despite advances in various treatment modalities resulting in improved local control, the long-term survival rates of patients with SCCOT has only marginally improved [1]. More than one-third of these tumors have regional lymph node metastasis already at diagnosis, significantly reducing the survival [2]. There is thus a great need to explore novel biomarkers enabling detection of tumors prior to clinical manifestation.

In 1953 Slaughter et al. introduced the field cancerization model, showing that oral cancers are surrounded by epithelium that is not unaffected by the cancerous development. When surgically 
removing an oral cancer, seemingly benign epithelium preconditioned to develop into cancer is accordingly left behind [3]. This could help explain the high incidence of local recurrence and multiple second primary tumors seen in patients with SCCOT and other types of squamous cell carcinoma of the head and neck (SCCHN). Fifty years later, genetically altered fields in the case of intraoral SCC can be detected as far as $7 \mathrm{~cm}$ from the tumor, implying that, although clinically normal, the main part of the oral cavity is affected by genetic alterations [4]. Recently, it has been suggested to consider field cancerization as representing an altered microenvironment rather than purely genetic alterations [5]. In the case of SCCOT, it can thus be of value to study not only the tumor itself but also the clinically tumor-free adjacent tongue tissue in order to map changes indicative of a tumor, novel or relapse, before any clinical signs are present.

Our own recent studies of clinically tumor-free tongue tissue contralateral to the SCCOT showed increased cytolytic $\mathrm{T}$ cell activity compared to normal tongue from volunteers with no evidence of SCCOT [6]. This cytolytic activity is a measure of cytotoxic proteins released by CD8 ${ }^{+} \mathrm{T}$ cells and NK cells, important players in the adaptive and innate immune responses, respectively [7].

A key factor in the process of cytotoxic T cell activation is the TAP1/TAP2 peptide transporter complex that brings antigen peptide substrates into the endoplasmic reticulum, where they are processed and loaded onto major histocompatibility class I (MHC-I) for export to the cell surface via the Golgi apparatus [8-10]. By downregulating the expression of transporter associated with antigen processing, TAP, causing loss of MHC I complexes on the surface, tumor cells can escape cytotoxic T cell recognition [11]. Mutations affecting TAP1 are frequently seen in human tumors and metastatic tumors more often show loss of function of TAP than primary tumors [11,12]. In addition, viruses such as human papilloma virus, HPV, cytomegalovirus, CMV, and Epstein Barr virus, EBV, downregulate TAP1 to avoid immune surveillance [11].

Based on our previous findings of an increased cytolytic activity in tumor-free tongue tissue contralateral to an SCCOT [6] remaining in the patient after treatment, we focused on TAP expression in these tissues.

\section{Results}

\subsection{Progressive Upregulation of TAP1 from Control to Tumor-Free to Tumor}

Analysis of previously published microarray results $[6,13]$ showed that TAP1 mRNA is significantly upregulated in tumor-free tongue compared to healthy controls (fold change $=1.65$ ), and further upregulated in tumor samples (Figure 1A). For TAP2, there was no significant difference in mRNA between tumor-free and healthy controls (Figure 1B), whereas a significant correlation between TAP1 and TAP2 levels was seen (Figure 1C). To confirm the microarray data, RT-qPCR was used for measuring TAP1 levels in 10 of the healthy tongue controls and 8 paired tumor-free and SCCOT samples. There was a significant correlation between microarray and RT-qPCR results for TAP1 (spearman correlation coefficient: 0.841, $p<0.001$; Figure 1D). 
A

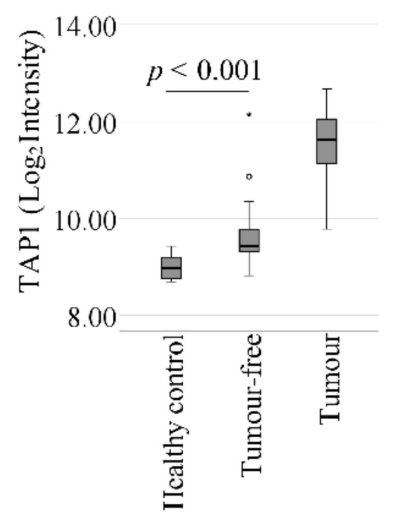

$\mathrm{C}$

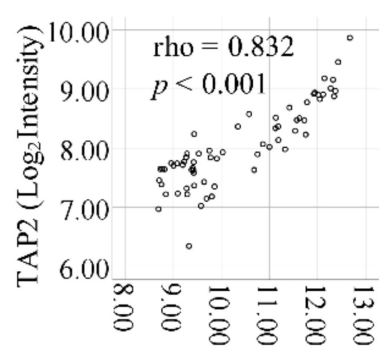

TAP1 ( $\log _{2}$ Intensity)
B

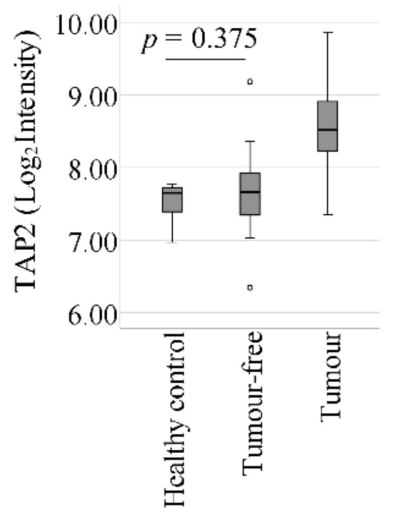

$\mathrm{D}$

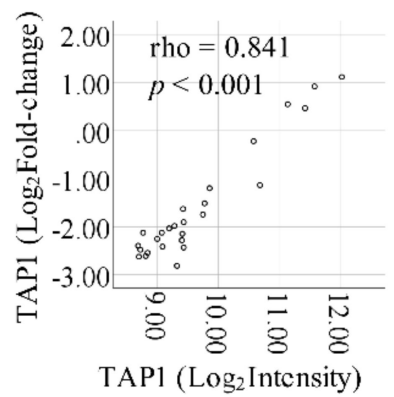

Figure 1. Microarray results of (A) TAP1 and (B) TAP2 mRNA levels in tongue from healthy volunteers, tumor-free samples and SCCOT samples. (C) Correlation between TAP1 and TAP2 levels $(p<0.001)$. (D) Real-time quantitative PCR (RT-qPCR) confirmation of microarray data for TAP1 (spearman correlation coefficient: $0.841, p<0.001$ ).

\subsection{Expression of TAP1 in Tumor-Free Samples Confers Prognostic Information}

Using univariate Cox regression survival analysis, we found that low expression of the TAP1 gene in tumor-free samples was significantly associated with better patient survival $(p<0.05$ for both overall and disease-free survival; Table 1). However, regarding TAP1 expression levels in tumor samples, no correlation to survival was found (Table 1). Previously, using the same samples, we reported that cytolytic activity in the tumor-free tongue is a useful prognostic factor [6]. Therefore, in the subsequent multivariate Cox regression analysis, we considered cytolytic activity, age at diagnosis, sex, clinical stage, T stage, and $\mathrm{N}$ stage as covariates. The results showed that TAP1 levels in tumor-free samples remained significant as an independent prognostic factor for overall $(p=0.031)$ and disease-free survival $(p=0.005)$ (Table 2). Finally, dividing patients into TAP1-high and TAP1-low groups according to the median TAP1 level in tumor-free samples demonstrated that patients with lower TAP1 mRNA levels in tumor-free samples had better overall ( $p=0.003$, Figure 2A) and disease-free survival $(p=0.002$, Figure 2B). As shown in Table 3, Fisher's exact test indicated that there was no significant correlation between TAP1 levels and different clinical factors $(p>0.05)$. 
Table 1. Univariate Cox regression analysis of TAP1 and TAP2.

\begin{tabular}{cccc}
\hline \multirow{2}{*}{ Sample } & Gene & $\begin{array}{c}\boldsymbol{p} \text {-Value (Cox-Regression Overall } \\
\text { Survival Analysis) }\end{array}$ & $\begin{array}{c}\boldsymbol{p} \text {-value (Cox-Regression } \\
\text { Disease-Free Survival Analysis) }\end{array}$ \\
\hline \multirow{2}{*}{ Tumor-free } & TAP1 & 0.042 & 0.026 \\
\cline { 2 - 4 } & TAP2 & 0.828 & 0.987 \\
\hline \multirow{2}{*}{ Tumor } & TAP1 & 0.772 & 0.892 \\
\cline { 2 - 4 } & TAP2 & 0.158 & 0.315 \\
\hline
\end{tabular}

Table 2. Univariate and multivariate Cox regression analysis of risk factors for survival.

\begin{tabular}{|c|c|c|c|c|c|c|c|c|c|}
\hline & & \multicolumn{4}{|c|}{ Univariate } & \multicolumn{4}{|c|}{ Multivariate } \\
\hline & & \multirow[t]{2}{*}{$p$-value } & \multirow{2}{*}{$\begin{array}{c}\text { Hazard } \\
\text { Ratio }\end{array}$} & \multicolumn{2}{|c|}{$\begin{array}{l}\text { 95\% Confidence } \\
\text { Interval }\end{array}$} & \multirow[t]{2}{*}{$p$-Value } & \multirow{2}{*}{$\begin{array}{c}\text { Hazard } \\
\text { Ratio }\end{array}$} & \multicolumn{2}{|c|}{$\begin{array}{l}\text { 95\% Confidence } \\
\text { Interval }\end{array}$} \\
\hline & & & & Lower & Upper & & & Lower & Upper \\
\hline \multirow{7}{*}{$\begin{array}{l}\text { Overall } \\
\text { survival }\end{array}$} & TAP1 & 0.042 & 1.836 & 1.023 & 3.294 & 0.031 & 12.650 & 1.267 & 126.283 \\
\hline & $\begin{array}{l}\text { Cytolytic } \\
\text { activity }\end{array}$ & 0.082 & 2.931 & 0.871 & 9.861 & 0.176 & 3.271 & 0.588 & 18.212 \\
\hline & Age & 0.607 & 1.010 & 0.972 & 1.049 & 0.799 & 1.007 & 0.954 & 1.063 \\
\hline & Sex & 0.124 & 2.531 & 0.775 & 8.271 & 0.217 & 2.877 & 0.538 & 15.394 \\
\hline & Stage & 0.013 & 1.952 & 1.149 & 3.318 & 0.064 & 0.046 & 0.002 & 1.201 \\
\hline & $\mathrm{T}$ & 0.012 & 1.912 & 1.152 & 3.172 & 0.034 & 33.982 & 1.308 & 882.785 \\
\hline & $\mathrm{N}$ & 0.011 & 2.482 & 1.233 & 4.996 & 0.364 & 1.819 & 0.500 & 6.622 \\
\hline \multirow{7}{*}{$\begin{array}{l}\text { Disease-free } \\
\text { survival }\end{array}$} & TAP1 & 0.029 & 1.844 & 1.066 & 3.189 & 0.005 & 19.886 & 2.480 & 159.446 \\
\hline & $\begin{array}{l}\text { Cytolytic } \\
\text { activity }\end{array}$ & 0.101 & 2.657 & 0.826 & 8.549 & 0.092 & 4.903 & 0.773 & 31.087 \\
\hline & Age & 0.415 & 1.016 & 0.978 & 1.055 & 0.414 & 1.023 & 0.968 & 1.081 \\
\hline & Sex & 0.099 & 2.509 & 0.841 & 7.486 & 0.236 & 2.399 & 0.565 & 10.188 \\
\hline & Stage & 0.033 & 1.659 & 1.042 & 2.641 & 0.013 & 0.024 & 0.001 & 0.460 \\
\hline & $\mathrm{T}$ & 0.028 & 1.674 & 1.057 & 2.650 & 0.010 & 52.561 & 2.581 & 1070.378 \\
\hline & $\mathrm{N}$ & 0.016 & 2.285 & 1.163 & 4.490 & 0.176 & 2.373 & 0.679 & 8.285 \\
\hline
\end{tabular}

A

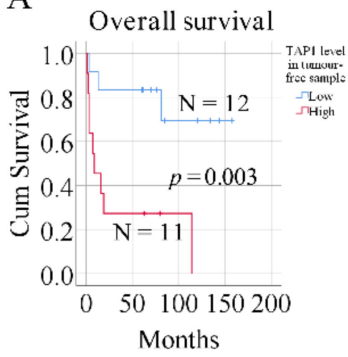

B

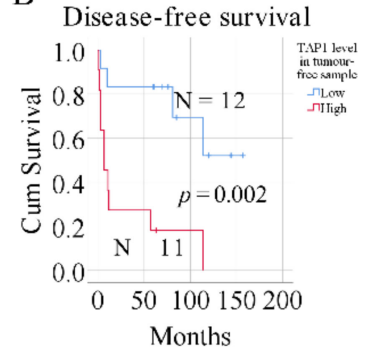

Figure 2. The influence of TAP1 levels in tumor-free samples on patient survival. Kaplan-Meier curves of overall (A) and disease-free (B) survival. Blue lines represent patients with low TAP1 levels, and red lines patients with high TAP1 levels. Log-rank test for overall $(p=0.003)$ and disease-free survival $(p=0.002) . \mathrm{N}=$ number of samples. 
Table 3. Clinical variables and their associations with TAP1.

\begin{tabular}{ccccc}
\hline & & \multicolumn{2}{c}{ TAP1 Level } & \multirow{2}{*}{$\boldsymbol{p}$-Value } \\
\cline { 2 - 4 } & & Low & High & \\
\hline \multirow{2}{*}{ Age (years) } & $\leq 65$ & 7 & 4 & 0.414 \\
\cline { 2 - 4 } & $>65$ & 5 & 7 & \\
\hline \multirow{2}{*}{ Sex } & Female & 4 & 7 & 0.220 \\
\cline { 2 - 4 } & Male & 8 & 4 & \\
\hline \multirow{2}{*}{ Stage } & I, II & 9 & 6 & 0.400 \\
\cline { 2 - 4 } & III, IV & 3 & 5 & \\
\hline \multirow{2}{*}{ T } & T1, T2 & 10 & 7 & 0.371 \\
\cline { 2 - 4 } & $\mathrm{T} 3, \mathrm{~T} 4$ & 2 & 4 & 0.640 \\
\hline \multirow{2}{*}{$\mathrm{N}$} & $\mathrm{N}=0$ & 10 & 8 & \\
\cline { 2 - 4 } & $\mathrm{N}>0$ & 2 & 3 & \\
\hline
\end{tabular}

To independently evaluate the prognostic value of TAP1, we downloaded gene expression and clinical data from The Cancer Genome Atlas, TCGA,-head and neck squamous cell carcinoma (HNSC) cohort. In this database, TAP1 levels (achieved from RNA sequencing) were available for 480 tumors and 42 tumor-free samples, showing significantly higher TAP1 levels in tumors $(p<0.001$, Figure $3 \mathrm{~A})$. TAP1 levels were also higher in SCCOT $(\mathrm{N}=121)$ compared to tumor-free controls $(\mathrm{N}=12, p<0.001$, Figure 3B). However, samples from different subsites of the head and neck were included in the external dataset as tumor-free controls, rather than tumor-free tongue contralateral to the SCCOT. Thus, no relevant comparison between TAP1 in tumor-free samples of SCCOT and the clinical outcome was possible using TCGA patient samples. Therefore, we used the median TAP1 mRNA level to divide the mixed group of 42 tumor-free samples into TAP1-low and TAP1-high groups. There was no significant association between TAP1 levels and different clinical factors (Fisher's exact test, $p>0.05$, Table 4). Kaplan-Meier survival analysis showed that low TAP1 in tumor-free tissues was significantly associated with better overall survival (log-rank test, $p$-value $=0.024$, Figure $4 \mathrm{~A}$ ). Cox regression also showed that TAP1-low patients had better overall survival than TAP1-high patients $(p=0.028)$, also when considering cytolytic activity, age at diagnosis, sex, stage, and $\mathrm{T}$ and $\mathrm{N}$ values as covariates $(p=0.011$, Table 5). Using Kaplan-Meier analysis on TAP1 levels in 41 out of 42 matched SCCOT samples with follow up data available, no difference in overall survival was found between TAP1-low and TAP1-high patients (Figure 4B). Nor was there a difference in overall survival between TAP1-low and TAP1-high patients when considering the 479 out of 480 tumor samples with follow-up data available from the TCGA dataset (Figure 4C).
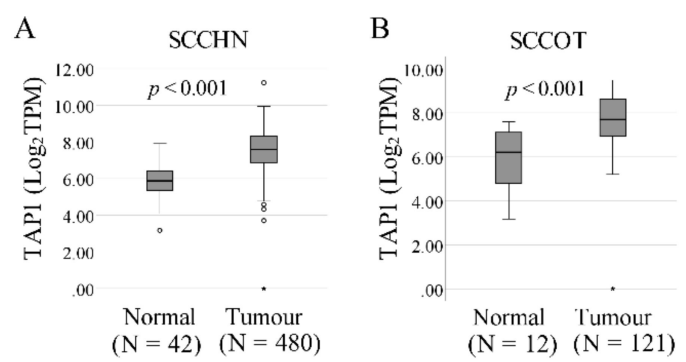

Figure 3. TCGA-HNSC (The Cancer Genome Atlas-head and neck squamous cell carcinoma) cohort data. Plots show TAP1 levels in tumors and tumor-free samples, the latter denominated "normal" in TCGA, for (A) the whole group of squamous cell carcinoma of the head and neck-SCCHN $(p<0.001)$ and (B) for squamous cell carcinoma of the tongue (SCCOT) only $(p<0.001)$. 
Table 4. Clinical variables and their associations with TAP1 (TCGA data).

\begin{tabular}{ccccc}
\hline & & \multicolumn{2}{c}{ TAP1 Level } & \multirow{2}{*}{$p$-Value } \\
\cline { 2 - 4 } & & Low & High & \\
\hline \multirow{2}{*}{ Age (years) } & $\leq 65$ & 15 & 10 & \multirow{2}{*}{0.346} \\
\cline { 2 - 4 } & $>65$ & 7 & 10 & \\
\hline \multirow{2}{*}{ Sex } & Female & 5 & 8 & \multirow{2}{*}{0.320} \\
\cline { 2 - 4 } & Male & 17 & 12 & \\
\hline \multirow{2}{*}{ Stage } & I, II & 17 & 17 & \multirow{2}{*}{0.700} \\
\cline { 2 - 4 } & III, IV & 5 & 3 & \multirow{2}{*}{1.000} \\
\cline { 2 - 4 } T & T1, T2 & 9 & 9 & \multirow{2}{*}{1.000} \\
\cline { 2 - 4 } N & $\mathrm{T} 3, \mathrm{~T} 4$ & 13 & 11 & \\
\cline { 2 - 4 } & $\mathrm{N}=0$ & 16 & 15 & 5 \\
\hline
\end{tabular}

A

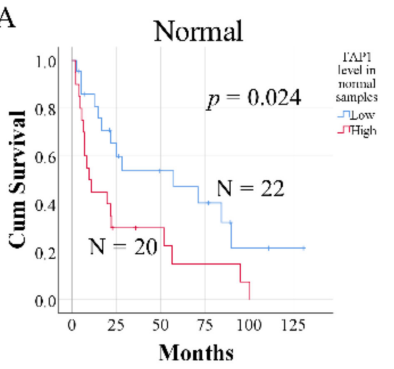

B

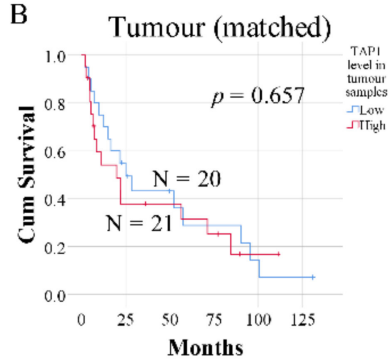

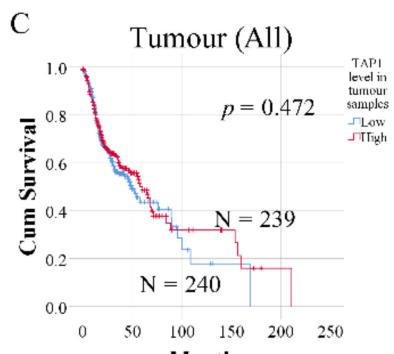

Months

Figure 4. The influence of TAP1 levels in tumor-free samples from the TCGA-HNSC cohort on patient survival. Kaplan-Meier curves of overall survival for (A) tumor-free samples (denominated "normal" by TCGA), (B) matched tumor samples, and (C) all SCCHN tumors available in the TCGA database. Blue lines represent patients with low TAP1 levels, and red lines indicate patients with high TAP1 levels. $\mathrm{N}=$ number of samples

Table 5. Survival analysis with Cox regression on tumor-free samples in the TCGA HNSC cohort.

\begin{tabular}{|c|c|c|c|c|c|c|c|c|}
\hline & \multicolumn{4}{|c|}{ Univariate } & \multicolumn{4}{|c|}{ Multivariate } \\
\hline & \multirow[t]{2}{*}{$p$-value } & \multirow{2}{*}{$\begin{array}{c}\text { Hazard } \\
\text { Ratio }\end{array}$} & \multicolumn{2}{|c|}{$\begin{array}{l}\text { 95\% Confidence } \\
\text { Interval }\end{array}$} & \multirow[t]{2}{*}{$p$-Value } & \multirow{2}{*}{$\begin{array}{c}\text { Hazard } \\
\text { Ratio }\end{array}$} & \multicolumn{2}{|c|}{$\begin{array}{l}\text { 95\% Confidence } \\
\text { Interval }\end{array}$} \\
\hline & & & Lower & Upper & & & Lower & Upper \\
\hline TAP1 (high vs. low) & 0.028 & 2.253 & 1.093 & 4.644 & 0.011 & 4.405 & 1.401 & 13.847 \\
\hline Cytolytic activity & 0.447 & 1.318 & 0.647 & 2.683 & 0.217 & 0.476 & 0.146 & 1.547 \\
\hline Age & 0.311 & 1.017 & 0.984 & 1.051 & 0.366 & 1.018 & 0.979 & 1.060 \\
\hline Sex & 0.554 & 0.786 & 0.355 & 1.743 & 0.994 & 1.003 & 0.421 & 2.388 \\
\hline Clinical stage & 0.125 & 1.340 & 0.922 & 1.950 & 0.632 & 1.275 & 0.472 & 3.445 \\
\hline T stage & 0.194 & 1.310 & 0.871 & 1.971 & 0.801 & 1.105 & 0.509 & 2.397 \\
\hline N stage & 0.074 & 1.711 & 0.949 & 3.086 & 0.408 & 1.441 & 0.606 & 3.426 \\
\hline
\end{tabular}

\section{Discussion}

Early detection of SCCOT improves its prognosis as well as diminishes the need for extensive surgical treatment. In the search for valuable prognostic factors, the clinically normal tissue adjacent to a tumor that remains in the patient after treatment has attracted attention. Field cancerization is a well-known phenomenon for tumors within the head and neck area [4] and we recently showed that 
increased cytolytic activity in clinically normal tongue contralateral to an SCCOT correlates to better survival [6]. Cytolytic activity is measured as levels of factors (perforin and granzymes) released by cytotoxic $\mathrm{CD} 8^{+} \mathrm{T}$ cells and NK cells, and high cytolytic activity is thus indicative of an immunologically active tissue.

The heterodimer TAP is an important factor in formation of the MHC I antigen, acting as a complex and important factor in $\mathrm{CD} 8^{+} \mathrm{T}$ cell immune surveillance [8]. The TAP proteins, TAP1 and TAP2, are essential for antigen processing [8]. Whereas levels of TAP2 were almost unchanged in the 21 tumor-free samples studied here, the group with TAP1 mRNA levels below the median showed significantly better overall and disease-free survival when considering age, sex, cytolytic activity, and tumor stage.

The results showed an inverse correlation between TAP1 and the previous results on cytolytic activity in clinically tumor-free tongue contralateral to the SCCOT in relation to prognosis. Whereas increased cytolytic activity could be part of the inflammatory response in the tumor vicinity and thus play a protective role, the importance of decreased levels of TAP1 is harder to explain as it is not well known how its expression is regulated under normal conditions. Whereas low levels of TAP1 are an indicator of better survival, increased levels could serve as a sign of malignancy in tumor-free tissue contralateral to a treated SCCOT. This is, however, debatable due to the difficulty of defining "high" levels in tumor-free samples. Importantly, downregulation of TAP1 in SCCHN has been reported previously [14-16]. A higher frequency of TAP down regulation has also been reported in metastatic compared to primary SCCHN [12]. By down regulating TAP causing loss of MHC class I antigen on the surface, tumors can escape cytotoxic $\mathrm{T}$ cell recognition [11]. Unexpectedly in our study, we found a gradual increase in TAP1 levels from healthy control to tumor-free to tumor samples. Conflicting results regarding the prognostic value of tumor TAP1 were also observed. When analyzing TAP1 in SCCOT, we did not find any correlation between expression levels and survival. In accordance with our mRNA data, TAP1 protein did not shown any correlation to survival in SCCHN tumors [14]. However, in esophageal cancer, upregulation of TAP1 protein in cancer tissues was found to be an unfavorable prognostic factor [17]. Differences between studies in terms of cancer subtypes and research methods, such as different assays and various scoring strategies, may be responsible for some of the discrepancies. In our group of SCCOTs, it could thus be interesting to map the expression of the TAP1 protein and its potential clinical relevance in comparison to the RNA-data shown here.

Overexpression of the TAP1 protein has been suggested as an indicator of aggressiveness in breast cancers, which is thought to be due either to a lower capacity of more advanced tumors to downregulate $\mathrm{TAP}$, or to a higher concentration of immune infiltrates in the microenvironment producing IFN- $\gamma$, which causes upregulation of the TAP subunits [18]. In colorectal cancer, decreased levels of TAP1 were seen in tumors with perineural invasion, making downregulation of TAP1 a prognostic factor for patients with stage I and II disease [19].

As TAP plays a key role in $\mathrm{CD} 8^{+} \mathrm{T}$ cell immune surveillance, it would be interesting to see if the levels of TAP influence the therapeutic outcome in SCCOT patients treated with immune checkpoint inhibitors such as PD-1 or PD-L1 antibodies.

In summary, the present findings illustrate the importance of studying the clinically tumor-free tongue contralateral to SCCOT in the search for relevant field changes that could be of diagnostic and/or prognostic importance. This tissue, remaining in the patient after treatment, is of utmost importance as it is easily accessible for different kinds of analyses at regular follow up. Our results, which show that TAP1 levels in tumor-free tongue contralateral to the SCCOT correlate with survival, are an important contribution to early diagnostics and follow up of SCCOT, improving our overall understanding of this complicated and severe disease. 


\section{Materials and Methods}

\subsection{Patient Material and Ethical Approval}

The study comprised a total of 31 patients ( 15 men and 16 women) with a median age of 64 years (range 19-87 years) treated surgically and/or with radiotherapy for SCCOT at the Department of Otorhinolaryngology and Head \& Neck Surgery, Norrland's University Hospital, Umeå, Sweden. Approval for the study was obtained by the local Ethical Committee at Umeå University (Dnr 08-003M). Written informed consent was obtained from each participant. All samples were collected before treatment. For patients with status "alive disease-free", the minimum follow up time was 5 years.

Biopsies had been taken from the tumor in 29 of the patients and from the clinically tumor-free tongue on the contralateral side of the tumor in 21 of these. From the remaining two patients with SCCOT, only tumor-free samples were available. Tongue biopsies from 14 healthy individuals served as the control group. Clinical information for patients and controls is shown in Table 6.

Table 6. Clinicopathological data on SCCOT patients and healthy controls.

\begin{tabular}{|c|c|c|c|c|c|c|c|c|c|c|}
\hline No & ID & Sample & Age & Sex & TNM & Stage & Localization \# & Status & $\begin{array}{l}\text { Follow-up } \\
\text { Months }\end{array}$ & $\begin{array}{l}\text { Months to } \\
\text { Recurrence }\end{array}$ \\
\hline 1 & $\mathrm{p} 40$ & 1 & 80 & Female & T4N2bM0 & IV & 3 & DWD & 1 & \\
\hline 2 & $\mathrm{p} 42$ & 1 & 68 & Female & T2N0M0 & II & 1 & DWD & 9 & 7 \\
\hline 3 & p14 & 2 & 77 & Female & T2N1M0 & III & 2 & DDF & 189 & \\
\hline 4 & p24 & 2 & 64 & Male & T1N0M0 & I & 1 & ADF & 195 & \\
\hline 5 & p29 & 2 & 64 & Female & T2N0M0 & II & 2 & DWD & 29 & 20 \\
\hline 6 & p68 & 2 & 62 & Male & T2N0M0 & II & 1 & DOD & 9 & 6 \\
\hline 7 & p70 & 2 & 71 & Male & T1N0M0 & I & 2 & $\mathrm{ADF}$ & 134 & \\
\hline 8 & $\mathrm{p} 82$ & 2 & 19 & Female & T4N0M0 & IV & 2 & DOD & 18 & 12 \\
\hline 9 & p83 & 2 & 64 & Female & T1N0M0 & I & 2 & $\mathrm{ADF}$ & 119 & \\
\hline 10 & p92 & 2 & 63 & Female & T2N0M0 & II & 2 & DOD & 20 & 6 \\
\hline 11 & p11 & 3 & 78 & Male & T2N0M0 & II & 2 & DWD & 3 & \\
\hline 12 & p35 & 3 & 24 & Female & T2N0M0 & II & 1 & DOD & 13 & 10 \\
\hline 13 & $\mathrm{p} 49$ & 3 & 52 & Female & $\mathrm{T} 4 \mathrm{~N} 2 \mathrm{cM} 0$ & IV & 3 & DWD & 3 & \\
\hline 14 & p51 & 3 & 74 & Male & T2N0M0 & II & 1 & $\mathrm{ADF}$ & 157 & \\
\hline 15 & p56 & 3 & 40 & Female & T2N2bM0 & IV & 3 & DOD & 16 & 12 \\
\hline 16 & p58 & 3 & 61 & Male & T1N0M0 & I & 1 & $\mathrm{ADF}$ & 144 & \\
\hline 17 & p59 & 3 & 68 & Female & T2N0M0 & II & 1 & DOD & 7 & \\
\hline 18 & p61 & 3 & 69 & Male & T4aN0M0 & IV & 3 & DDF & 81 & \\
\hline 19 & p65 & 3 & 81 & Female & T2N0M0 & II & 3 & $\mathrm{ADF}$ & 134 & 114 \\
\hline 20 & p73 & 3 & 80 & Male & T4aN0M0 & IV & 3 & DOD & 19 & 11 \\
\hline 21 & p76 & 3 & 58 & Male & T4aN0M0 & IV & 3 & DDF & 114 & \\
\hline 22 & p79 & 3 & 60 & Male & T1N0M0 & I & 2 & $\mathrm{ADF}$ & 120 & \\
\hline 23 & p85 & 3 & 87 & Female & T2N0M0 & II & 1 & DOD & 2 & 2 \\
\hline 24 & p98 & 3 & 31 & Male & T2N0M0 & II & 3 & $\mathrm{ADF}$ & 85 & \\
\hline 25 & p105 & 3 & 63 & Male & T1N0M0 & I & 2 & $\mathrm{ADF}$ & 80 & 57 \\
\hline 26 & p111 & 3 & 31 & Female & T1N0M0 & I & 2 & $\mathrm{ADF}$ & 76 & \\
\hline
\end{tabular}


Table 6. Cont.

\begin{tabular}{|c|c|c|c|c|c|c|c|c|c|c|}
\hline No & ID & Sample $^{a}$ & Age & Sex & TNM & Stage & Localization \# & Status & $\begin{array}{l}\text { Follow-up } \\
\text { Months }\end{array}$ & $\begin{array}{l}\text { Months to } \\
\text { Recurrence }\end{array}$ \\
\hline 27 & p119 & 3 & 66 & Male & T2N0M0 & II & 2 & $\mathrm{ADF}$ & 70 & \\
\hline 28 & p124 & 3 & 54 & Male & T4aN2bM0 & 0 IV & 3 & DOD & 3 & \\
\hline 29 & p131 & 3 & 74 & Female & T2N0M0 & II & 2 & $\mathrm{ADF}$ & 63 & \\
\hline 30 & p137 & 3 & 71 & Female & T2N0M0 & II & 2 & $\mathrm{ADF}$ & 61 & \\
\hline 31 & p138 & 3 & 50 & Male & T2N1M0 & III & 2 & $\mathrm{ADF}$ & 60 & \\
\hline 32 & NT1 & 4 & 32 & Female & & & & & & \\
\hline 33 & NT2 & 4 & 49 & Female & & & & & & \\
\hline 34 & NT3 & 4 & 25 & Female & & & & & & \\
\hline 35 & NT4 & 4 & 30 & Male & & & & & & \\
\hline 36 & NT5 & 4 & 27 & Male & & & & & & \\
\hline 37 & NT6 & 4 & 42 & Female & & & & & & \\
\hline 38 & NT7 & 4 & 32 & Female & & & & & & \\
\hline 39 & NT8 & 4 & 41 & Female & & & & & & \\
\hline 40 & NT9 & 4 & 35 & Female & & & & & & \\
\hline 41 & NT10 & 4 & 57 & Male & & & & & & \\
\hline 42 & NT11 & 4 & 45 & Male & & & & & & \\
\hline 43 & NT12 & 4 & 37 & Male & & & & & & \\
\hline 44 & NT13 & 4 & 48 & Female & & & & & & \\
\hline 45 & NT14 & 4 & 59 & Female & & & & & & \\
\hline
\end{tabular}

\subsection{RNA Isolation and Gene Expression Profiling}

As previously reported, RNA isolation and gene expression profiling were performed on 29 tumors, 23 tumor-free samples, and 14 healthy controls [6,13]. Briefly, biopsies were fresh-frozen in liquid nitrogen for further storage until RNA extraction. A total of $200 \mathrm{ng}$ RNA was used for gene expression profiling with Illumina HumanHT-12 v4 Expression BeadChip (Illumina Inc., San Digo, CA, USA). Raw data are available at ArrayExpress under accession numbers E-MTAB-4678 and E-MTAB-5534.

\subsection{Prognostic Factor Analysis}

Cox's regression model was performed for survival analysis. Multivariate Cox regression analysis was also performed, with cytolytic activity, sex, age at diagnosis, and TNM stage as covariates. Patients were divided into high or low expression groups according to the median gene expression value in the tumor-free samples. Kaplan-Meier with log-rank tests were used to compare survival curves between groups. Fisher's exact test was used to investigate the correlation between gene expression and clinical factors. All tests were conducted in IBM SPSS Statistics 26 (IBM Corp., Armonk, NY, USA). A two-sided $p$-value $<0.05$ was considered significant.

\subsection{Confirmation of Microarray Data Using RT-qPCR}

Microarray data were confirmed using reverse transcription quantitative PCR (RT-qPCR) of tongue tissue from 10 of the healthy controls and 8 of the paired tumor/tumor-free samples from patients with SCCOT, using the QuantStudio 6 Flex real-time PCR system (Thermo Fisher Scientific, Waltham, MA, USA). Custom primers used were TAP1 (forward: CTGGACTCCCTCAGGGCTAT, reverse: GGTTTCCGGATCAATGCTCG). As reference genes, RPL13A 
(forward: CACGAGGTTGGCTGGAAGTA, reverse: ACGTTCTTCTCGGCCTGTTT) and GAPDH (forward: GCCCTCAACGACCACTTTGT, reverse: TTACTCCTTGGAGGCCATGTG) were used. All primers were obtained from Thermo Fisher Scientific. Gene expression was quantified using the relative standard curve method. Spearman correlation coefficient (rho) was calculated to evaluate correlation strength between microarray and RT-qPCR results.

\subsection{The Cancer Genome Atlas (TCGA) Data Collection and Analysis}

Gene expression data from the TCGA head and neck cancer cohort was downloaded using the International Cancer Genome Consortium (ICGC) data portal (https://dcc.icgc.org/). Clinical data were downloaded from TCGA's data portal (https://portal.gdc.cancer.gov). A prognostic factor analysis, as above, was performed to study the impact of gene expression on clinical outcome.

Author Contributions: Conceptualization, X.G., P.J.C., R.F., and K.N.; Formal analysis, X.G., N.A., L.B., T.W., L.W., N.S., and K.Z.; Investigation, X.G. and L.W.: Writing-Original draft preparation, X.G. and N.A., wrote the manuscript; Writing-Review \& Editing, P.J.C., R.F., K.N., L.B., T.W., N.S., and K.Z.; Supervision, X.G. and K.N.; Funding Acquisition, K.N. and P.J.C. All authors have read and commented on the manuscript and approved of the submitted version.

Funding: This study was supported by Lion's Cancer Research Foundation, Umeå University; The Swedish Cancer Society (contract number 18 0542); Umeå University; Region Västerbotten; Ministry of Health Czech Republic, conceptual development of research organization (MMCI, 00209805).

Conflicts of Interest: The authors declare no conflict of interest.

\section{References}

1. Sgaramella, N.; Gu, X.; Boldrup, L.; Coates, P.J.; Fåhraeus, R.; Califano, L.; Tartaro, G.; Colella, G.; Spaak, L.N.; Strom, A.; et al. Searching for New Targets and Treatments in the Battle Against Squamous Cell Carcinoma of the Head and Neck, with Specific Focus on Tumours of the Tongue. Curr. Top. Med. Chem. 2018, 18, 214-218. [CrossRef] [PubMed]

2. Sano, D.; Myers, J.N. Metastasis of squamous cell carcinoma of the oral tongue. Cancer Metastasis Rev. 2007, 26, 645-662. [CrossRef] [PubMed]

3. Slaughter, D.P.; Southwick, H.W.; Smejkal, W. Field cancerization in oral stratified squamous epithelium; clinical implications of multicentric origin. Cancer 1953, 6, 963-968. [CrossRef]

4. Braakhuis, B.J.; Tabor, M.P.; Kummer, J.A.; Leemans, C.R.; Brakenhoff, R.H. A genetic explanation of Slaughter's concept of field cancerization: Evidence and clinical implications. Cancer Res. 2003, 63, 1727-1730. [PubMed]

5. Lochhead, P.; Chan, A.T.; Nishihara, R.; Fuchs, C.S.; Beck, A.H.; Giovannucci, E.; Ogino, S. Etiologic field effect: Reappraisal of the field effect concept in cancer predisposition and progression. Mod. Pathol. 2015, 28, 14-29. [CrossRef] [PubMed]

6. Gu, X.; Boldrup, L.; Coates, P.J.; Fahraeus, R.; Wang, L.; Wilms, T.; Norberg-Spaak, L.; Sgaramella, N.; Nylander, K. High immune cytolytic activity in tumor-free tongue tissue confers better prognosis in patients with squamous cell carcinoma of the oral tongue. J. Pathol. Clin. Res. 2019, 5, 240-247. [CrossRef] [PubMed]

7. Rosenberg, J.; Huang, J. CD8+ T cells and NK cells: Parallel and complementary soldiers of immunotherapy. Curr. Opin. Chem. Eng. 2018, 19, 9-20. [CrossRef] [PubMed]

8. Abele, R.; Tampe, R. The ABCs of Immunology: Structure and Function of TAP, the Transporter Associated with Antigen Processing. Physiology 2004, 19, 216-224. [CrossRef] [PubMed]

9. Ritz, U.; Seliger, B. The Transporter Associated With Antigen Processing (TAP): Structural Integrity, Expression, Function, and Its Clinical Relevance. Mol. Med. 2001, 7, 149-158. [CrossRef] [PubMed]

10. Eggensperger, S.; Tampe, R. The transporter associated with antigen processing: A key player in adaptive immunity. Biol. Chem. 2015, 396, 1059-1072. [CrossRef] [PubMed]

11. Lankat-Buttgereit, B.; Tampe, R. The Transporter Associated With Antigen Processing: Function and Implications in Human Diseases. Physiol. Rev. 2002, 82, 187-204. [CrossRef] [PubMed]

12. Bandoh, N.; Ogino, T.; Katayama, A.; Takahara, M.; Katada, A.; Hayashi, T.; Harabuchi, Y. HLA class I antigen and transporter associated with antigen processing downregulation in metastatic lesions of head 
and neck squamous cell carcinoma as a marker of poor prognosis. Oncol. Rep. 2010, 23, 933-939. [CrossRef] [PubMed]

13. Boldrup, L.; Gu, X.; Coates, P.J.; Norberg-Spaak, L.; Fåhraeus, R.; Laurell, G.; Wilms, T.; Nylander, K. Gene expression changes in tumor free tongue tissue adjacent to tongue squamous cell carcinoma. Oncotarget 2017, 8, 19389-19402. [CrossRef] [PubMed]

14. Meissner, M.; Reichert, T.E.; Kunkel, M.; Gooding, W.; Whiteside, T.L.; Ferrone, S.; Seliger, B. Defects in the Human Leukocyte Antigen Class I Antigen Processing Machinery in Head and Neck Squamous Cell Carcinoma: Association with Clinical Outcome. Clin. Cancer Res. 2005, 11, 2552-2560. [CrossRef] [PubMed]

15. Han, W.; Pan, H.; Jiang, L.; Wei, K.; Zou, D.; Zhang, Z. A novel approach to rescue immune escape in oral squamous cell carcinoma: Combined use of interferon- $\gamma$ and LY294002. Oncol. Rep. 2011, 25, 181-187. [PubMed]

16. Wei, H.; Hongya, P.; Linlin, J.; Mujiang, A.; Kuijie, W.; Duohong, Z.; Qingang, H.; Zhiyuan, Z. IFN- $\gamma$ enhances the anti-tumour immune response of dendritic cells against oral squamous cell carcinoma. Arch. Oral Biol. 2011, 56, 891-898. [CrossRef] [PubMed]

17. Tanaka, K.; Tsuchikawa, T.; Miyamoto, M.; Maki, T.; Ichinokawa, M.; Kubota, K.C.; Shichinohe, T.; Hirano, S.; Ferrone, S.; Dosaka-Akita, H.; et al. Down-regulation of Human Leukocyte Antigen class I heavy chain in tumors is associated with a poor prognosis in advanced esophageal cancer patients. Int. J. Oncol. 2012, 40, 965-974. [CrossRef] [PubMed]

18. Henle, A.M.; Nassar, A.; Puglisi-Knutson, D.; Youssef, B.; Knutson, K.L. Downregulation of TAP1 and TAP2 in early stage breast cancer. PLOS ONE 2017, 12, e0187323. [CrossRef] [PubMed]

19. Ling, A.; Löfgren-Burström, A.; Larsson, P.; Li, X.; Wikberg, M.L.; Öberg, Å.; Stenling, R.; Edin, S.; Palmqvist, R. TAP1 down-regulation elicits immune escape and poor prognosis in colorectal cancer. Oncolmmunology 2017, 6, e1356143. [CrossRef] [PubMed]

(C) 2020 by the authors. Licensee MDPI, Basel, Switzerland. This article is an open access article distributed under the terms and conditions of the Creative Commons Attribution (CC BY) license (http://creativecommons.org/licenses/by/4.0/). 